\title{
Saberes Plurais para o Jornalismo: crítica de gênero e contribuições femininas nas Teorias do Jornalismo
}

\author{
Gean Oliveira Gonçalves' \\ Naiana Rodrigues da Silva ${ }^{2}$ \\ Cicélia Pincer Batista ${ }^{3}$
}

\section{Resumo}

Passados cerca de 50 anos de reflexões críticas sobre o jornalismo no Brasil a partir do primeiro estudo de pós-graduação no campo, deparamo-nos com significativas tentativas de compreender as contribuições e as abordagens dos pesquisadores de jornalismo para uma Teoria do Jornalismo. Neste artigo, averiguamos como o conhecimento e as pesquisas de mulheres são apresentados nas bibliografias dos cursos de jornalismo no País. Em um momento de discussões sobre o ensinoaprendizado como experiência de inclusão, interessa-nos provocar perturbações sobre as implicações de ensinar jornalismo a partir de um pensamento majoritariamente masculino, o qual é construído como cânone e como experiência universal. Para tanto, fizemos um levantamento de programas de disciplinas de teorias do Jornalismo em 27 cursos de graduação, um de cada unidade da federação. O resultado revelou uma desigualdade epistemológica em virtude das relações de gênero na produção de conhecimento sobre o jornalismo.

Palavras-chave: Epistemologia. Ensino de jornalismo. Relações de gênero.

\footnotetext{
1 Jornalista. Doutorando do Programa de Pós-Graduação em Ciências da Comunicação da Escola de Comunicações e Artes da Universidade de São Paulo (PPGCOM/USP). Pesquisador do grupo de pesquisa Epistemologia do Diálogo Social (ECA-USP). Bolsista do CNPq - Brasil. E-mail: geangoncalves@usp.br.

2 Professora assistente do curso de Jornalismo da Universidade Federal do Ceará (UFC) e doutoranda em Ciências da Comunicação, na Escola de Comunicações e Artes (ECA), da Universidade de São Paulo (USP). Pesquisadora do Centro de Pesquisa em Comunicação e Trabalho (CPCT/ECA/USP) e do grupo de pesquisa PráxisJor (UFC). E-mail: naianarodrigues@usp.br.

3 Doutora em Ciências da Comunicação pela Escola de Comunicações e Artes da Universidade de São Paulo (ECA/USP), professora do curso de Jornalismo da Escola Superior de Propaganda e Marketing (ESPMSP) e pesquisadora do grupo de pesquisa Epistemologia do Diálogo Social (ECA-USP). E-mail: cicelia.batista@espm.br.
}

Revista Pauta Gerall-Estudos em Jornalismo, Ponta Grossa, vol. 6, n. 2, p. 171-193, Dez/Jul, 2019. 


\title{
Plural Knowledge for Journalism: gender criticism and female contributions in Journalism Theories
}

\begin{abstract}
About 50 years after critical reflections on journalism in Brazil from the first postgraduate study in the field, we are faced with significant attempts to understand the contributions and approaches of journalism researchers to a Journalism Theory. In this article, we investigate how women's knowledge and research are presented in the bibliographies of journalism courses in the country. In a moment of discussion about teaching-learning as an experience of inclusion, we are interested in causing disturbs on the implications of teaching journalism from a mostly male thinking, which is constructed as a canon and as a universal experience. To this, we surveyed journalism theory discipline programs in 27 undergraduate courses, one from each federation unit. The result revealed an epistemological inequality due to gender relations in the knowledge production about journalism.
\end{abstract}

Keywords: Epistemology. Journalism teaching. Gender relations.

\section{Introdução}

Parece de fundamental relevância para um conjunto de protagonistas sociais, entre eles muitos docentes, que o contexto da sala de aula precisa ser uma experiência pedagógica que respeite, acolha e honre os grupos em vulnerabilidade e seus saberes, que possamos cruzar as barreiras erguidas pela raça, pelo gênero, pela sexualidade, pela classe social e por outras diferenças.

Além de responder às demandas e lutas por visibilidade e legitimação de vários movimentos e grupos da sociedade civil - que, como ressalta Kilomba (2019), vêm transformando radicalmente o pensamento e o vocabulário contemporâneos -, o reconhecimento desta necessidade, inclusive, ganhou dimensão político-institucional mais ampla com a inclusão, por parte do Ministério da Educação, de Diretrizes Curriculares Nacionais voltadas à inclusão da "Educação em Direitos Humanos" (Resolução no 1/2012 do CNE) e da "Educação das relações Étnico-Raciais e para o ensino da História e Cultura Afro-Brasileira e Africana" (Resolução no 1, de 17/06/2004 do CNE) como componentes obrigatórias a serem observadas pelos sistemas de ensino brasileiros e suas instituições. 


\section{REVISTA PAUTA GERAL}

\section{ESTUDOS EM JORNALISMO}

10.5212/RevistaPautaGeral.v.6.i2.00013

No âmbito mais específico dos cursos de Jornalismo, além da exigência de se atender às componentes mais gerais apontadas anteriormente, destacamos o fato de que suas Diretrizes Curriculares Nacionais estabelecem em seu Artigo 5que

O concluinte do curso de Jornalismo deve estar apto para o desempenho profissional de jornalista, com formação acadêmica generalista, humanista, crítica, ética e reflexiva, capacitando-o, dessa forma, a atuar como produtor intelectual e agente da cidadania, capaz de responder, por um lado, à complexidade e ao pluralismo característicos da sociedade e da cultura contemporâneas [...] (CNE, 2013, p. 2).

No entanto, e a despeito destas demandas e exigências sociais e institucionais, pode-se dizer que ainda impera, no modo de ensinar, o depósito de informações e a reiteração de cânones intelectuais que têm suas contribuições constituídas e marcadas majoritariamente pela perspectiva do sexismo, do racismo, da heterossexualidade, do colonialismo, portanto, práticas didáticas fixas, absolutas e situadas no hegemônico. E essa realidade não parece ser diferente na experiência do ensino de jornalismo.

Contudo, é possível imaginar modos de ensino e de experiência de aprendizado diferentes, com o intuito de questionar as parcialidades que reforçam os sistemas de dominação e proporcionar liberdade a grupos diversificados de alunos. Para tanto, uma das primeiras e mais importantes condições é reconhecer que a maioria dos professores aprende a ensinar imitando os pares. Daí porque não é estranho encontrar docentes que, em sala de aula, adotam posturas racistas, machistas, homofóbicas e transfóbicas. Esse tipo de atitude não apenas é prejudicial à experiência de ensino-aprendizagem, mas oblitera as possibilidades de uma formação cidadã e efetivamente dialógica e inclusiva, já que tende a produzir momentos de tensão e confronto, reforçando e naturalizando processos históricos e sociais de assujeitamento e de desigualdades estruturais.

Nesse sentido é que hooks (2013) recomenda, ao se propor mudanças de paradigmas na educação, que se leve em consideração o receio e o medo dos docentes:

[...] a maioria de nós frequentamos escolas onde o estilo de ensino refletia a noção de uma única norma de pensamento e experiência, a qual éramos encorajados a crer que fosse universal. Isso vale tanto para os professores não brancos quanto para os brancos. A maioria de nós aprendemos ensinar imitando esse modelo. Como consequência, muitos professores se perturbam com as implicações políticas de uma educação multicultural, pois têm medo de perder o controle da turma caso não haja um modo único de abordar um tema, mas sim modos múltiplos e referências múltiplas (HOOKS, 2013, p. 51). 


\section{REVISTA PAUTA GERAL}

\section{ESTUDOS EM JORNALISMO}

10.5212/RevistaPautaGeral.v.6.i2.00013

Vivemos em um momento no qual se busca a inclusão e o respeito por todos, ou seja, fazer da educação um contexto democrático, o que inclui as vivências de pessoas negras, mulheres, indígenas, da juventude e de pessoas LGBT, entre outros grupos. Viver uma experiência de educação em que os paradigmas estejam em obras escritas por "grandes homens brancos europeus" não parece coerente com a pluralidade e com a busca de alteridade - ainda mais quando se pensa no jornalismo como uma profissão e como uma instituição social voltada à mediação autoral responsável por criar condições para o diálogo dos diferentes, para a escuta de todas as vozes sociais.

Neste contexto, nossa pesquisa é motivada pela percepção de que, muitas vezes, a vontade de incluir, nos cursos de Jornalismo, não se faz acompanhar pelo mesmo empenho em atribuir legitimidade e respeito aos trabalhos de autoras, de intelectuais negros, de novas epistemologias. Assim é que, nas suas matrizes teóricas, por exemplo, se reconhece o trabalho de autores pioneiros, de estudiosos de grande referência espalhados por universidades por todo o Brasil, nos Estados Unidos e na Europa -, mas pouca atenção se proporciona às mulheres que contribuíram e ainda contribuem para o conhecimento do/no Jornalismo.

É essa percepção que pretendemos averiguar e atravessar nas próximas páginas; perguntando como as mulheres que teorizam e elaboram noções de compreensão do fenômeno jornalístico estão sendo abordadas. Elas são apresentadas? Há ênfase nas suas contribuições, especialmente nos conteúdos e bibliografia adotadas nas disciplinas de Teorias do Jornalismo?

\section{Epistemologias feministas e plurais}

A epistemologia contemporânea vem efetuando, há algum tempo, uma forte crítica à noção de que o sujeito (que é um produtor de sentidos) é capaz de capturar com objetividade, pelo rigor acadêmico, o que está fora dele. Nesse sentido, foi colocada em vigor a interpretação de que as técnicas de produção do conhecimento são também meios de produção simbólica e que, portanto, a autoria do conhecimento é marcada por subjetividades, pelos discursos sociais, pelas contradições, pelas disputas de poder vigentes e pelos desafios de um tempo histórico.

No fim dos anos 1990, Rago (1998) escreveu que as feministas não apenas têm produzido uma crítica contundente ao modo dominante de produção do conhecimento científico, mas as mulheres trazem uma experiência histórica e cultural diferenciada da 


\title{
REVISTA PAUTA GERAL
}

\section{ESTUDOS EM JORNALISMO}

10.5212/RevistaPautaGeral.v.6.i2.00013

masculina, que acaba por provocar mutações e desestabilizações na produção do saber. Para Rago,

\begin{abstract}
o feminismo propõe uma nova relação entre teoria e prática. Delineia-se um novo agente epistêmico, não isolado do mundo, mas inserido no coração dele, não isento e imparcial, mas subjetivo e afirmando sua particularidade. Ao contrário do desligamento do cientista em relação ao seu objeto de conhecimento, o que permitiria produzir um conhecimento neutro, livre de interferências subjetivas, clama-se pelo envolvimento do sujeito com seu objeto (RAGO, 1998, p. 11, grifo da autora).
\end{abstract}

As epistemologias feministas, na análise de Rago, são uma ampla crítica cultural da racionalidade cartesiana que opera em um campo ensimesmado, "valendo-se de categorias reflexivas incapazes de pensar a diferença" (RAGO, 1998, p. 4). Para Rago, as críticas feministas à ciência apontam que o conhecimento é constituído a partir de um conceito universal de homem, que remete a uma identidade branca, europeia, burguesa e heterossexual; perspectiva que é assegurada pelas noções de objetividade e neutralidade que garantem a veracidade do conhecimento, fundantes para as Ciências Sociais pela via do positivismo. Portanto, o discurso científico é predominantemente masculino, pois é construído como efeito de discursos, práticas e relações da centralidade dos homens na sociedade.

No entanto, com a ampliação de um conhecimento sobre as mulheres e, agora, sobre as relações de gênero, há a incorporação de um discurso contra hegemônico que resulta em desestabilizações, abandonos de conceitos, questionamentos e a releitura de concepções absolutas e totalizadoras dos fenômenos do mundo, no qual

Feministas assumidas ou não, as mulheres forçam a inclusão dos temas que falam de si, que contam sua própria história e de suas antepassadas e que permitem entender as origens de muitas crenças e valores, de muitas práticas sociais frequentemente opressivas e de inúmeras formas de desclassificação e estigmatização (RAGO, 1998, p. 13).

Em diálogo com Rago, Haraway (1995), destaca a potência da visão daqueles posicionados como subjugados, como subalternos no processo de decodificação tecnocientífica; são elas e eles dotados da capacidade de estabelecer interpretações em conjunto, já que afirmam uma posição parcial no projeto de construção do conhecimento. Suas posições não têm a pretensão de constituir um conhecimento racional universal, que pertence a todos os lugares, que fixa verdades, pelo contrário, resistem à ideia de fechamento e à lógica do ponto de vista único; compõem objetividade com subjetividades e, desse modo, constituem mapas e redes de compreensão. A ciência torna-se, assim, a 


\title{
REVISTA PAUTA GERAL
}

\section{ESTUDOS EM JORNALISMO}

10.5212/RevistaPautaGeral.v.6.i2.00013

constituição de espaços solidários de "visões cacofônicas e vozes visionárias" (HARAWAY, 1995):

\begin{abstract}
Estou argumentando a favor de políticas e epistemologias de alocação, posicionamento e situação nas quais parcialidade e não universalidade é a condição de ser ouvido nas propostas a fazer de conhecimento racional. São propostas a respeito da vida das pessoas; a visão desde um corpo, sempre um corpo complexo, contraditório, estruturante e estruturado, versus a visão de cima, de lugar nenhum, do simplismo (HARAWAY, 1995, p. 30).
\end{abstract}

Outra contribuição a esse debate advém dos ensaios epistemológicos de Medina (2005). A autora concebe algumas rupturas transdisciplinares que incidem no conhecimento sobre o jornalismo, cuja atuação estaria amarrada ao paradigma cientificista-positivista do século XIX. Para Medina (2005), a força social do jornalismo no imaginário coletivo e profissional advém do rigor da investigação, do estatuto de veracidade e da credibilidade ao resgatar comportamentos e histórias dos protagonistas sociais no contemporâneo. De certa forma, a metodologia do jornalismo incorpora um estatuto científico masculino pela aposta em valores e normas de ação comumente associadas ao gênero masculino, como desempenho, velocidade, observação, levantamento de dados e entrevistas com as fontes de informação. Segundo Medina,

O pressuposto da objetividade, exigência metodológica para uma cobertura isenta dos fatos, na realidade encobre os complexos contextos. Estes são filtrados por valores e opções ideológicas, quase sempre não conscientes da parte do autor. Para atuar numa situação humana altamente cifrada pela cultura, pelas múltiplas forças políticas, econômicas, sociais e individualizadas nos sujeitos-protagonistas, o profissional da informação de atualidade precisaria de uma capacidade sobre-humana para decifrá-la (MEDINA, 2005, p. 196).

Compreendemos que o processo de encobrir destacado por Medina (2005) significa que a cultura jornalística é marcada por percepções de mundo de uma suposta experiência global de vida, pelo dogma da busca da verdade, que é próprio de uma perspectiva de dominação masculina, cuja racionalidade estabelece um sistema sujeito-objeto que enfatiza a diferença como subalternidade e produz desigualdade e vulnerabilidade. A assimetria de gênero está, portanto, nas entranhas do jornalismo, incidindo sobre o discurso jornalístico, sobre as trajetórias de trabalho de mulheres jornalistas, e encontra-se com as desigualdades epistemológicas, colando-se às pesquisas científicas e com as relações de poder, também pautadas no gênero, no contexto das universidades, reproduzindo-se assim na relação ensino-aprendizado. 


\section{REVISTA PAUTA GERAL}

\section{ESTUDOS EM JORNALISMO}

10.5212/RevistaPautaGeral.v.6.i2.00013

Mas, assim como as epistemologias feministas, Medina (2005) aposta, como saída, na epistemologia da complexidade e dos afetos, marcada pela relação sujeito-sujeito, pelo pensar complexo, sentir solidário e pelo agir criativo. Ela reforça o papel das narrativas de afetos, de histórias de vida, de depoimentos dos protagonistas sociais, portanto, que atravessam e transcendem a relação. Da colheita das marcas humanas do outro e da decifração complexa, em suma, que caminha por descobrir e não por revelar, pois

[...] só com essa energia afetiva se pode pôr em questão os perigos de uma racionalidade falaciosa, simplificadora, com o tônus judicativo de quem se sente desafeto. A sedução pelo enquadramento do desconhecido ou mal compreendido em conceitos e pré-conceitos aumenta no ambiente racionalizador e arrogante e tende a se esfumaçar no corpo-a-corpo com o espantosamente diferente, mas respeitável (MEDINA, 2005, p. 202).

Em termos propositivos é significativo pensar ainda na contribuição de Moraes e Veiga da Silva (2019) ao refletirem sobre a subjetividade como estratégia que desestabiliza as práticas jornalísticas estruturadas em um sistema epistemológico masculino (que também é capitalista, racista, ocidental, heteronormativo). As autoras mostram os modos como o jornalismo opera simbolicamente em tramas que historicamente relegam determinados sujeitos e grupos às margens, ou seja, valem-se do método científico, o mesmo que funda o paradigma da modernidade.

Moraes e Veiga da Silva (2019, p. 4) declaram que "o jornalismo é partícipe, atuando como um mediador e também sendo por eles perpassado, adquirindo conhecimentos através dos conceitos e características similares às da ciência, especialmente em alguns métodos e epistemologias hegemônicas para a validação de uma 'verdade objetiva'". Dessa maneira, ambas as autoras relacionam a subjetividade como um lugar de transgressão das práticas jornalísticas convencionais:

Acreditamos que um caminho para desestabilizar os modos redutores de representação perpetrados pela imprensa é a adoção do que chamamos de jornalismo de subjetividade, denominação que carrega alguma provocação ao sublinhar justamente aquilo que sempre foi negado pela prática, apesar de estar em seu bojo, entranhada pela epistemologia regente. A partir da crítica feminista, entendemos que a subjetividade (e todos os elementos que estariam relacionados a ela, tais como a emoção, - corpo, as visões de mundo dos sujeitos-profissionais), atributo convencionado como feminino, ocupa as bases da hierarquia no jornalismo. Alijada da objetivação jornalística, por não ser considerada "prenhe da razão dualista e cartesiana", a subjetividade é suprimida não apenas na linguagem, que visa à impessoalidade no discurso com fins de assegurar neutralidade, totalidade e valor de verdade. É suprimida também, em grande parte, nas reflexões críticas sobre as práticas, tanto pelos profissionais que as desempenham quanto por boa parte dos 


\title{
REVISTA PAUTA GERAL
}

\section{ESTUDOS EM JORNALISMO}

10.5212/RevistaPautaGeral.v.6.i2.00013

estudos que predominaram historicamente no campo (MORAES; VEIGA DA SILVA, 2019, p. 13).

Nessa perspectiva, objetividade e subjetividade se integram, passam a significar uma produção simbólica no campo jornalístico que considera as posições de jornalistas e protagonistas sociais em termos de classe, gênero, localidade geográfica, racialidade e demais marcações culturais. Assim, o jornalismo não deixa de ignorar o meio no qual vivemos, os desenhos da realidade e dos assujeitamentos dos sujeitos.

Diante de tais contribuições sobre a constituição do saber científico e do saber jornalístico, volta-se a interrogante: o ensino contemporâneo em jornalismo conforma ou transforma? Distante de um debate essencialista, em que a mera presença feminina qualifica a pluralidade, mas pensando que ela pode contribuir para uma polissemia e polifonia às teorias do jornalismo, perguntamo-nos se há assinalado nos cursos de jornalismo e, com o devido prestígio, as contribuições femininas ao campo.

\section{A feminização do jornalismo}

A cultura e os ideais do jornalismo são forjados tanto no campo científico quanto no âmbito do trabalho sobre a referencialidade do masculino, contradizendo assim a própria realidade. Diferentes estudos sobre o trabalho jornalístico e o perfil dos jornalistas no Brasil e até mesmo em outros países mostram que as mulheres são numericamente majoritárias nos espaços de jornalismo (LELO, 2019; FÍGARO, 2018; DEUZE; WITSCHGE, 2014; FÍGARO, NONATO, GROHMANN, 2013; MICK, LIMA, 2013):

\begin{abstract}
No estado de São Paulo, segundo dados do Sindicato dos Jornalistas, compilados a partir da Relação Anual de Informações Sociais (RAIS) havia, em 2006, 11.771 jornalistas empregados. Desses, 52,09\%, ou seja, 6.131 eram mulheres (Costa, 2008, p. 3). Essa presença feminina se manifesta numericamente de forma diferente nos setores profissionais. Havia menos mulheres em rádio, TV e internet; tradicionalmente, as mulheres estavam presentes no setor de imprensa, revistas e no chamado extra redação (assessorias, por exemplo). Mas isso vem mudando. Elas são numericamente bastante presentes em novas iniciativas do trabalho jornalístico a partir das redes sociais (FIGARO, 2018).
\end{abstract}

Segundo Figaro, a mudança do perfil do trabalhador no jornalismo se delineia desde os anos 1980 e a proeminência do gênero feminino foi constatada por estudos após a primeira década dos anos 2000. Dentre estes, o de Mick e Lima (2013), cujo objetivo era traçar um perfil do jornalista brasileiro, verificou que $63,7 \%$ da categoria profissional são compostos por mulheres jornalistas. A feminização do jornalismo é um fenômeno conectado 


\section{REVISTA PAUTA GERAL}

\section{ESTUDOS EM JORNALISMO}

10.5212/RevistaPautaGeral.v.6.i2.00013

com as mudanças produtivas do trabalho. Figaro (2018) nos lembra que a densidade urbana aliada com o crescimento da população feminina e com a qualificação educacional das mulheres, na segunda metade do século XX, são alguns índices macroestruturais que explicam a maior presença delas em postos de trabalho de um modo geral.

Essa prevalência, contudo, não pode ser confundida com privilégio e poder. Antunes (1999) chama a atenção para o fato de que a força de trabalho feminina, nos países capitalistas avançados, tem sido relegada aos trabalhos do tipo part time (trabalho em tempo parcial), à precarização e à desregulamentação. Tal pacote de desigualdades é completado com a apropriação da polivalência e da multiatividade das mulheres pelo capitalismo, pois a dupla jornada da mulher - na fábrica com o trabalho produtivo e no lar, com o trabalho reprodutivo - são essenciais para a manutenção do capital.

O mundo do trabalho do jornalismo, por sua vez, mimetiza essas desigualdades ao, por exemplo, remunerar de modo inferior as mulheres. Pelo menos, foi o que verificaram Mick e Lima (2013), ao notarem que a maioria das jornalistas brasileiras tem uma média salarial de até cinco salários mínimos, e poucas são as que recebem uma remuneração superior a esta faixa de proventos. O salário, porém, não é o único protagonista do drama da discriminação da mulher no mundo do trabalho do jornalismo. Figaro (2018) cita ainda a ocupação de cargos e funções considerados inferiores no jornalismo, assim como as dificuldades enfrentadas pelas trabalhadoras para ascender na carreira dentro das organizações jornalísticas. Isso só para citar desigualdades referentes à atividade de trabalho, pois além destas, as mulheres ainda enfrentam investidas violentas dos homens, de dimensões moral e sexual, em seus espaços de trabalho.

Lelo (2019, p.123), em sua tese sobre a reconfiguração produtiva do jornalismo, reuniu outros estudos sobre a feminização do trabalho jornalístico e apontou que o gradativo aumento da presença das mulheres nas redações não significou diretamente a "reconfiguração dos quadros de gestão, a suplantação das segregações por cargos ou editorias (LACHOVER, 2005; DE BRUIN, 2014) ou ainda à almejada igualdade de oportunidades e a feminização das condutas organizacionais". A feminização, conforme o autor, torna-se, sob essa perspectiva, um mero marcador de diferença que reitera a lógica dicotômica dos gêneros e naturaliza os papéis sociais.

Esse cenário faz da desconstrução de normas, práticas e valores masculinizados uma urgência para o campo jornalístico, afinal, como pondera Figaro (2018, p. 581), a 


\title{
REVISTA PAUTA GERAL
}

\section{ESTUDOS EM JORNALISMO}

10.5212/RevistaPautaGeral.v.6.i2.00013

justificativa para essa condição de subalternidade a qual a mulher é relegada se deve a um compósito de fatores históricos:

\begin{abstract}
A explicação cabível deve ser dada por um entendimento que extrapole o aspecto individual e compreenda a situação da mulher no âmbito mais amplo do que significa o poder sobre o corpo feminino e o controle dele no sentido da perpetuação da estrutura social e da lógica da exploração do mercado. Trata-se, sem dúvida, conforme Bourdieu (2002), de uma tradição incrustada na vida cotidiana, reiterada pela família, pela escola e pelos meios de comunicação. São atitudes e comportamentos naturalizados que colocam a mulher em lugar inferior, subalterno, o que justificaria o trabalho redobrado, jornadas duplicadas e extensas, o papel de cuidadora do lar e dos filhos, entre outras responsabilidades caracterizadas como da mulher. Mas, além desses aspectos, o imperativo é o da dominação de classe por meio da submissão da personalidade, da exploração do tempo, da descaracterização do espírito de cidadania e de autonomia da mulher. Como força de trabalho mais barata, submissa e reprodutora do status quo, a mulher - e, no caso, a mulher jornalista torna-se ou vítima dessa estrutura ou vítima e guardiã dela.
\end{abstract}

Se a escola é uma das instituições com potencial para legitimar as opressões e, ao mesmo tempo, transformar a realidade e os saberes relativos ao jornalismo, tanto o saberfazer (rotinas, práticas e técnicas) quanto o saber-ser (condutas, valores e princípios), , apresenta-se mandatório adotar posturas estruturais que subvertam a espiral de opressões contra as mulheres nas arenas do trabalho e da educação. Uma dessas ações com verve reparadora é exatamente a simetria entre as produções acadêmicas autorais de pesquisadoras e pesquisadores em jornalismo.

O campo da Comunicação, em particular do Jornalismo, desde o início das pesquisas em nível de Pós-Graduação contou com a presença significativa das mulheres:

As mulheres são maioria entre as pós-graduandas da Comunicação, é fato. Contudo, a legitimação dessas mulheres como intelectuais do campo parece ser mais complexa do que para os homens. As mulheres são minoria tanto na premiação da INTERCOM como da SBPjor na categoria sênior, que condecora a trajetória acadêmica de pesquisadores; apenas uma premiação da área tem nome de mulher; as jornalistas escolhidas para serem estudadas são poucas e têm reconhecimento muito mais por sua produção literária do que jornalística. Quando se pensa em referências canônicas da Comunicação e Jornalismo, são nomes masculinos que surgem (ALMEIDA, 2018, p. 134-135).

Almeida (2018) destaca a presença de Cremilda Medina, da Universidade de São Paulo, e de Zélia Leal Adghirni, da Universidade de Brasília, como algumas das pesquisadoras pioneiras e de referência do campo. Entre lideranças, Almeida (2018) chama atenção para aquelas que presidiram a Associação Brasileira de Pesquisadores em Jornalismo (SBPJor): Dione Moura, Claudia Lago e Monica Martinez, e para as que foram 


\section{REVISTA PAUTA GERAL}

\section{ESTUDOS EM JORNALISMO}

10.5212/RevistaPautaGeral.v.6.i2.00013

celebradas com o Prêmio Adelmo Genro Filho, na categoria Sênior, que se destina a reconhecer a qualidade do trabalho acadêmico realizado nas universidades ou nos centros/institutos de pesquisa, bem como a consolidar a identidade e memória do campo científico: Christa Berger, Graça Caldas, Zelia Leal Adghirni, Dulcília Schroeder Buitoni, Cremilda Medina e, mais recentemente, Beatriz Corrêa Pires Dornelles.

Apesar da celebração dessas mulheres pelo campo, a lógica do apagamento das pesquisadoras e teóricas do Jornalismo teve uma forte incidência em uma edição da revista Pauta Geral (v. 5, n. 2, 2018) que visava, exatamente, a publicização da expressividade atual das teorias do jornalismo. Ao explorar os aportes teóricos brasileiros, o dossiê temático do periódico apresentou dez estudiosos do Jornalismo. No entanto, a seleção contou apenas com um artigo que explora as contribuições de uma mulher - no caso, sobre Cremilda Medina -, ao passo que os demais versaram sobre o pensamento de homens pioneiros na constituição do campo acadêmico.

Face a essa realidade de celebração pontual e apagamento convencional das investigadoras, qual é o lugar das mulheres-pesquisadoras no ensino de jornalismo?

\section{Decisões metodológicas e resultados}

A problemática aqui exposta nos conduziu à realização de um estudo qualitativo que, conforme Deslauriers e Kèrisit (2008), atende a uma variedade de objetivos nas Ciências Sociais, dentre os quais está o aprofundamento de fenômenos complexos. Intuito que condiz com nossa pesquisa, afinal queremos interpelar o campo do jornalismo sobre o lugar das mulheres teóricas na realidade formativa. Essa visada nos autorizou a construir um desenho de pesquisa exploratório, sem a ambição de construir categorias universais, mas sim de elaborar aproximações com a realidade e apontar caminhos para pesquisas com maior fôlego que versem sobre as intersecções entre jornalismo e feminismo.

Para alcançar os objetivos propostos, analisamos as obras de referência indicadas como conteúdo para saber/reconhecer as teorias do jornalismo nos programas disciplinares dos cursos de jornalismo nas cinco regiões do país e, consequentemente, mensuramos a presença das pesquisadoras nesses conteúdos referenciais. Levando-se em consideração que o universo de nossa pesquisa é composto por 417 cursos de graduação presenciais em jornalismo, foi necessária a construção de filtros para obter uma amostra factível, visto que a coleta de dados seria realizada de modo manual e não por meio de softwares. 


\section{REVISTA PAUTA GERAL}

\section{ESTUDOS EM JORNALISMO}

10.5212/RevistaPautaGeral.v.6.i2.00013

Optamos por uma amostragem não-probabilística, fechada e de contraste, que não está preocupada em estabelecer representatividade numérica, mas revelar as heterogeneidades dentro de um conjunto de sujeitos ou objetos que partilham de uma situação comum (PIRES, 2008, p. 199). Conforme o autor, essa amostragem pode ser elaborada a partir de variáveis gerais, relacionadas a marcas sociodemográficas, por exemplo, e variáveis específicas, que dizem respeito ao problema de pesquisa e a hipóteses teóricas levantadas pelo pesquisador.

Nesta investigação, adotamos como variáveis para a composição do corpus a ser estudado os seguintes critérios gerais: a) diversidade territorial b) cursos de graduação em universidades públicas federais ou estaduais; c) transparência e acessibilidade por meio da disponibilização pública, via internet, das ementas e programas das disciplinas que compõem a matriz curricular do respectivo curso de graduação. A variável específica, que também foi desdobrada na análise dos resultados, versou sobre a consulta às ementas (conteúdo programático) e identificação da bibliografia recomendada tanto como conteúdo obrigatório quanto complementar nas disciplinas relativas ao estudo das Teorias do Jornalismo.

Diante desses critérios, nossa amostra foi composta por 27 cursos de graduação situados nas 27 unidades da federação. Destes, apenas quatro não apresentaram em suas grades curriculares disciplinas relativas ao ensino das Teorias do Jornalismo. Entre os 23 cursos restantes, quatro não apresentaram em seus programas livros ou artigos relativos às teorias do jornalismo. Portanto, o corpus para análise foi reduzido a 19 cursos de graduação de instituições públicas de ensino.

O levantamento apresentou o retrato, que pode ser conferido na tabela 01 , de obras bibliográficas e de autores e autoras do Jornalismo: 


\section{REVISTA PAUTA GERAL}

\section{ESTUDOS EM JORNALISMO}

10.5212/RevistaPautaGeral.v.6.i2.00013

Tabela 01: Autoria feminina nas bibliografias sobre Teorias do Jornalismo

\begin{tabular}{|c|c|c|c|c|c|}
\hline Estado & $\begin{array}{l}\text { Instituição de } \\
\text { Ensino } \\
\text { Superior }\end{array}$ & Disciplina & $\begin{array}{l}\text { Obras na } \\
\text { Bibliografia }\end{array}$ & $\begin{array}{c}\text { Total } \\
\text { de } \\
\text { Autores }\end{array}$ & $\begin{array}{l}\text { Pesquisadoras } \\
\text { do Jornalismo }\end{array}$ \\
\hline Acre $(A C)$ & $\begin{array}{l}\text { Universidade } \\
\text { Federal do } \\
\text { Acre (UFAC) }\end{array}$ & $*_{4}$ & $*$ & $*$ & $*$ \\
\hline $\begin{array}{l}\text { Amazonas } \\
\text { (AM) }\end{array}$ & $\begin{array}{l}\text { Universidade } \\
\text { Federal do } \\
\text { Amazonas } \\
\text { (UFAM) }\end{array}$ & $*$ & $*$ & $*$ & $*$ \\
\hline Amapá (AP) & $\begin{array}{l}\text { Universidade } \\
\text { Federal do } \\
\text { Amapá } \\
\text { (UNIFAP) }\end{array}$ & $\begin{array}{l}\text { Teorias do } \\
\text { Jornalismo }\end{array}$ & 7 & 7 & 0 \\
\hline Pará (PA) & $\begin{array}{l}\text { Universidade } \\
\text { Federal do } \\
\text { Pará (UFPA) }\end{array}$ & $*$ & $*$ & $*$ & $*$ \\
\hline $\begin{array}{l}\text { Rondônia } \\
\text { (RO) }\end{array}$ & $\begin{array}{l}\text { Universidade } \\
\text { Federal de } \\
\text { Rondônia }\end{array}$ & $\begin{array}{l}\text { Teorias do } \\
\text { Jornalismo }\end{array}$ & 23 & 30 & 12 \\
\hline
\end{tabular}

${ }_{4}$ A IES não disponibiliza material pedagógico para identificar a disciplina de Teorias do Jornalismo, assim como as ementas e o conteúdo bibliográfico.

Revista Pauta Geral-Estudos em Jornalismo, Ponta Grossa, vol. 6, n. 2, p. 171-193, Dez/Jul, 2019. 
REVISTA PAUTA GERAL

ESTUDOS EM JORNALISMO

10.5212/RevistaPautaGeral.v.6.i2.00013

\begin{tabular}{|c|c|c|c|c|c|}
\hline Roraima (RR) & $\begin{array}{l}\text { Universidade } \\
\text { Federal de } \\
\text { Roraima } \\
\text { (UFRR) }\end{array}$ & $\begin{array}{l}\text { Teorias do } \\
\text { Jornalismo }\end{array}$ & 10 & 9 & 1 \\
\hline $\begin{array}{l}\text { Tocantins } \\
\text { (TO) }\end{array}$ & $\begin{array}{l}\text { Universidade } \\
\text { Federal do } \\
\text { Tocantins } \\
\text { (UFT) }\end{array}$ & $\begin{array}{l}\text { Teorias do } \\
\text { Jornalismo }\end{array}$ & 11 & 14 & 3 \\
\hline Alagoas (AL) & $\begin{array}{l}\text { Universidade } \\
\text { Federal de } \\
\text { Alagoas } \\
\text { (UFAL) }\end{array}$ & $\begin{array}{l}\text { Fundamentos e } \\
\text { Teorias do } \\
\text { Jornalismo }\end{array}$ & 13 & 13 & 3 \\
\hline Bahia (BA) & $\begin{array}{l}\text { Universidade } \\
\text { Federal da } \\
\text { Bahia (UFBA) }\end{array}$ & $\begin{array}{l}\text { Teorias do } \\
\text { Jornalismo }\end{array}$ & 10 & 8 & 2 \\
\hline Ceará (CE) & $\begin{array}{l}\text { Universidade } \\
\text { Federal do } \\
\text { Ceará (UFC) }\end{array}$ & $\begin{array}{l}\text { Teorias do } \\
\text { Jornalismo }\end{array}$ & 14 & 16 & 2 \\
\hline $\begin{array}{l}\text { Maranhão } \\
\text { (MA) }\end{array}$ & $\begin{array}{l}\text { Universidade } \\
\text { Federal do } \\
\text { Maranhão }\end{array}$ & $\begin{array}{l}\text { Teorias do } \\
\text { Jornalismo }\end{array}$ & 7 & 7 & 1 \\
\hline Paraíba (PB) & $\begin{array}{l}\text { Universidade } \\
\text { Federal da } \\
\text { Paraíba } \\
\text { (UFPB) }\end{array}$ & $\begin{array}{l}\text { Teorias do } \\
\text { Jornalismo }\end{array}$ & 20 & 17 & 4 \\
\hline
\end{tabular}

Revista Pauta Geral-Estudos em Jornalismo, Ponta Grossa, vol. 6, n. 2, p. 171-193, Dez/Jul, 2019. 
REVISTA PAUTA GERAL

ESTUDOS EM JORNALISMO

10.5212/RevistaPautaGeral.v.6.i2.00013

\begin{tabular}{|c|c|c|c|c|c|}
\hline $\begin{array}{c}\text { Pernambuco } \\
(\mathrm{PE})\end{array}$ & $\begin{array}{l}\text { Universidade } \\
\text { Federal de } \\
\text { Pernambuco }\end{array}$ & $\begin{array}{l}\text { Teoria do } \\
\text { Jornalismo }\end{array}$ & * & * & $*$ \\
\hline Piauí (PI) & $\begin{array}{c}\text { Universidade } \\
\text { Federal do } \\
\text { Piauí }\end{array}$ & $\begin{array}{l}\text { Teoria do } \\
\text { Jornalismo }\end{array}$ & $*$ & $*$ & $*$ \\
\hline $\begin{array}{l}\text { Rio Grande } \\
\text { do Norte } \\
\text { (RN) }\end{array}$ & $\begin{array}{l}\text { Universidade } \\
\text { Federal do } \\
\text { Rio Grande } \\
\text { do Norte }\end{array}$ & $\begin{array}{l}\text { Teorias do } \\
\text { Jornalismo }\end{array}$ & 12 & 15 & 6 \\
\hline Sergipe (SE) & $\begin{array}{l}\text { Universidade } \\
\text { Federal do } \\
\text { Sergipe (UFS) }\end{array}$ & $\begin{array}{l}\text { Teorias do } \\
\text { Jornalismo }\end{array}$ & $*$ & $*$ & $*$ \\
\hline $\begin{array}{c}\text { Distrito } \\
\text { Federal (DF) }\end{array}$ & $\begin{array}{l}\text { Universidade } \\
\text { de Brasília } \\
\text { (UnB) }\end{array}$ & $\begin{array}{l}\text { Teorias do } \\
\text { Jornalismo }\end{array}$ & 8 & 11 & 2 \\
\hline Goiás (GO) & $\begin{array}{l}\text { Universidade } \\
\text { Federal de } \\
\text { Goiás (UFG) }\end{array}$ & $\begin{array}{l}\text { Teorias do } \\
\text { Jornalismo }\end{array}$ & 8 & 7 & 2 \\
\hline $\begin{array}{l}\text { Mato Grosso } \\
\text { (MT) }\end{array}$ & $\begin{array}{l}\text { Universidade } \\
\text { Federal do } \\
\text { Mato Grosso } \\
\text { (UFMT) }\end{array}$ & * & $*$ & $*$ & * \\
\hline
\end{tabular}

Revista Pauta Gerall-Estudos em Jornalismo, Ponta Grossa, vol. 6, n. 2, p. 171-193, Dez/Jul, 2019. 
REVISTA PAUTA GERAL

ESTUDOS EM JORNALISMO

10.5212/RevistaPautaGeral.v.6.i2.00013

\begin{tabular}{|c|c|c|c|c|c|}
\hline $\begin{array}{l}\text { Mato Grosso } \\
\text { do Sul (MS) }\end{array}$ & $\begin{array}{l}\text { Universidade } \\
\text { Federal do } \\
\text { Mato Grosso } \\
\text { do Sul (UFMS) }\end{array}$ & $\begin{array}{l}\text { Teorias do } \\
\text { Jornalismo }\end{array}$ & 8 & 13 & 4 \\
\hline $\begin{array}{l}\text { Espírito Santo } \\
\text { (ES) }\end{array}$ & $\begin{array}{l}\text { Universidade } \\
\text { Federal do } \\
\text { Espírito Santo } \\
\text { (UFES) }\end{array}$ & $\begin{array}{c}\text { Teorias e Práticas } \\
\text { Jornalísticas }\end{array}$ & $*$ & $*$ & * \\
\hline $\begin{array}{l}\text { Minas Gerais } \\
\text { (MG) }\end{array}$ & $\begin{array}{l}\text { Universidade } \\
\text { Federal de } \\
\text { Minas Gerais } \\
\text { (UFMG) }\end{array}$ & $\begin{array}{l}\text { Teorias do } \\
\text { Jornalismo }\end{array}$ & 9 & 10 & 2 \\
\hline $\begin{array}{c}\text { Rio de } \\
\text { Janeiro (RJ) }\end{array}$ & $\begin{array}{l}\text { Universidade } \\
\text { Federal do } \\
\text { Rio de } \\
\text { Janeiro } \\
\text { (UFRJ) }\end{array}$ & $\begin{array}{l}\text { Teorias do } \\
\text { Jornalismo }\end{array}$ & 3 & 3 & 0 \\
\hline $\begin{array}{l}\text { São Paulo } \\
\text { (SP) }\end{array}$ & $\begin{array}{l}\text { Universidade } \\
\text { de São } \\
\text { Paulo5 (USP) }\end{array}$ & $\begin{array}{c}\text { Leituras } \\
\text { Contemporâneas } \\
\text { do Jornalismo }\end{array}$ & 24 & 23 & 6 \\
\hline
\end{tabular}

${ }^{5}$ A USP não possui disciplina nomeada Teorias do Jornalismo. Porém, a ementa da disciplina Leituras Contemporâneas do Jornalismo busca contribuir com uma reflexão conceitual do jornalismo, daí ter integrado a pesquisa.

Revista Pauta Geral-Estudos em Jornalismo, Ponta Grossa, vol. 6, n. 2, p. 171-193, Dez/Jul, 2019. 
REVISTA PAUTA GERAL

ESTUDOS EM JORNALISMO

10.5212/RevistaPautaGeral.v.6.i2.00013

\begin{tabular}{|c|c|c|c|c|c|}
\hline Paraná (PR) & $\begin{array}{c}\text { Universidade } \\
\text { Estadual de } \\
\text { Ponta } \\
\text { Grossa6 } \\
\text { (UEPG) }\end{array}$ & $\begin{array}{c}\text { Teorias do } \\
\text { Jornalismo I e II }\end{array}$ & 20 & 23 & 6 \\
\hline $\begin{array}{c}\text { Santa } \\
\text { Catarina } \\
\text { (SC) }\end{array}$ & $\begin{array}{c}\text { Universidade } \\
\text { Federal de } \\
\text { Santa } \\
\text { Catarina } \\
\text { (UFSC) }\end{array}$ & $\begin{array}{c}\text { Teoria do } \\
\text { Jornalismo }\end{array}$ & 21 & 30 & 10 \\
\hline $\begin{array}{c}\text { Rio Grande } \\
\text { do Sul (RS) }\end{array}$ & $\begin{array}{c}\text { Universidade } \\
\text { Federal de } \\
\text { Santa Maria } \\
\text { (UFSM) }\end{array}$ & $\begin{array}{c}\text { Teoria do } \\
\text { Jornalismo }\end{array}$ & 7 & 7 & 3 \\
\hline
\end{tabular}

Fonte: elaboração dos autores.

O mapeamento da composição bibliográfica dos cursos de jornalismo selecionados implicou ainda na identificação das obras com autoria de mulheres. A partir dele, reconhecemos as autoras e por qual contribuição de pesquisa e/ou ensaio elas são mais lembradas. Abaixo, seguem os nomes das cinco autoras mais recorrentes e suas obras:

- Beatriz Marocco e Christa Berger:

BERGER, Christa; MAROCCO, Beatriz (Org.). A era glacial do jornalismo: teorias sociais da imprensa. V. 2. Porto Alegre: Sulina, 2008.

BERGER, Christa; MAROCCO, Beatriz (Org.). A era glacial do jornalismo: teorias sociais da imprensa. V. 1. Porto Alegre: Sulina, 2006.

- Cremilda Medina: ${ }^{6}$ A UEPG possui as disciplinas Teorias do Jornalismo I e Teorias do Jornalismo II. Ambas foram
consideradas.

Revista Pauta Gerall-Estudos em Jornalismo, Ponta Grossa, vol. 6, n. 2, p. 171-193,

Dez/Jul, 2019. 


\section{REVISTA PAUTA GERAL}

\section{ESTUDOS EM JORNALISMO}

10.5212/RevistaPautaGeral.v.6.i2.00013

MEDINA, Cremilda. A arte de tecer o presente: narrativa e cotidiano. São Paulo: Summus, 2003.

MEDINA, Cremilda. Notícia, um produto à venda: jornalismo na sociedade urbana e industrial. São Paulo: Summus, 1988.

MEDINA, Cremilda de Araújo. Entrevista: o Diálogo Possível, São Paulo, Ática, 1986.

- Marcia Benetti:

BENETTI, Marcia, FONSECA, Virginia Pradelina da Silveira (Org.). Jornalismo e acontecimento: mapeamentos críticos. Florianópolis: Insular, 2010.

BENETTI, Marcia e LAGO, Claudia. Metodologia da Pesquisa em Jornalismo. Petrópolis: Vozes, 2007.

- Virginia Fonseca:

FONSECA, Virgínia. Indústria de notícias: capitalismo e novas tecnologias no jornalismo contemporâneo. Porto Alegre: UFRGS, 2008.

BENETTI, Marcia, FONSECA, Virginia Pradelina da Silveira (Org.). Jornalismo e acontecimento: mapeamentos críticos. Florianópolis: Insular, 2010.

Para dimensionar as principais autoras referenciadas, elaboramos uma nuvem de palavras que proporciona a visualização com ênfase nas repetições: 


\section{REVISTA PAUTA GERAL}

\section{ESTUDOS EM JORNALISMO}

10.5212/RevistaPautaGeral.v.6.i2.00013

Figura 01: Autoras com mais proeminência nas disciplinas de Teorias do Jornalismo

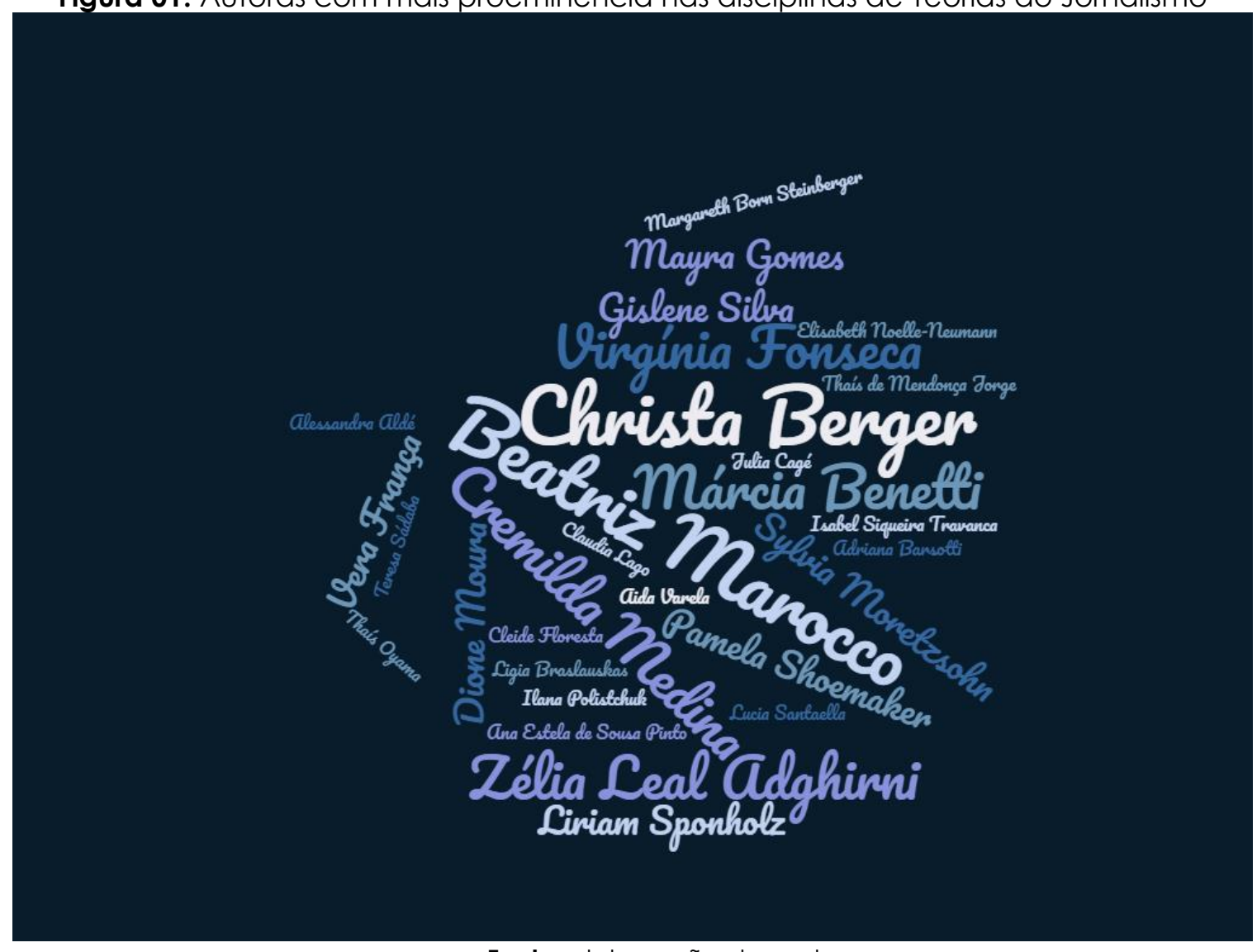

Fonte: elaboração dos autores.

Os resultados indicam que a autoria feminina não alcança paridade com obras elaboradas por homens que compõem os estudos em Jornalismo. Elas alcançam cerca de 29,3\% de representação junto ao conteúdo autoral para as Teorias do Jornalismo, o que totaliza 235 indicações bibliográficas. Na tabela apresentada, elas também não compõem a metade da composição bibliográfica em nenhum curso selecionado. Nas disciplinas de fundamentação teórica, o olhar masculino prevalece. Os estudantes são, aparentemente, privados de conhecer a variedade e multiplicidade do pensamento jornalístico e os modelos tensionados por elas.

A obra de autoria de mulher com maior repercussão é o duplo volume de $A$ Era Glacial do Jornalismo - Teorias Sociais da Imprensa (Editora Sulina, 2006, 2008). As coletâneas, organizadas por Beatriz Marocco e Christa Berger, apresentam as teorias e percepções de intelectuais alemães e norte-americanos sobre o jornalismo e suas articulações com a sociedade. Com textos de Max Weber, Ferdinand Tönnies, Otto Groth, Robert Park, Edward Ross e Walter Lippmann, até então não traduzidos para o português 


\section{REVISTA PAUTA GERAL}

\section{ESTUDOS EM JORNALISMO}

10.5212/RevistaPautaGeral.v.6.i2.00013

e pouco reconhecidos, estimulam uma análise sobre os primórdios de uma ciência da imprensa. Curiosamente, as pesquisadoras da Universidade do Vale do Rio dos Sinos são as com maior inserção no ensino de graduação das universidades selecionadas, porém, isso não ocorre por meio de uma obra que contemple um pensamento epistemológico autoral, tampouco feminino.

Virgínia Fonseca e Marcia Benetti, da Universidade Federal do Rio Grande do Sul, e Cremilda Medina, da Universidade de São Paulo, são as pesquisadoras cujas obras autorais são mais apresentadas no ensino de graduação.

Entre as autoras gaúchas, Virginia Pradelina da Silveira Fonseca atua como docente e pesquisadora dos seguintes temas: Jornalismo, Sociologia do Jornalismo, História do Jornalismo e Ética Jornalística. Sua obra mais referenciada foi Indústria de notícias: capitalismo e novas tecnologias no jornalismo contemporâneo (UFRGS, 2008), fruto de sua pesquisa de doutorado, defendida em 2005 na Universidade Federal do Rio Grande do Sul e ganhadora do prêmio Capes de 2006 na área de Ciências Sociais Aplicadas. Nela, Fonseca reflete sobre como a etapa atual e global do capitalismo se manifesta na organização jornalística e nas rotinas produtivas da informação e das notícias.

O segundo livro referenciado da autora possui coautoria com Marcia Benetti: Jornalismo e acontecimento: mapeamentos críticos (Insular, 2010). Nesta obra, as autoras se dedicam a investigar o conceito de acontecimento em perspectiva multidisciplinar para formar uma epistemologia do acontecimento jornalístico e articulam tal mapeamento com as teorias do jornalismo (estudos aplicados sobre noticiabilidade, agendamento e enquadramento).

A docente e pesquisadora Marcia Benneti, com forte atuação em estudos sobre o jornalismo como gênero discursivo e contrato de comunicação, é lembrada pela obra Metodologia de pesquisa em jornalismo (Editora Vozes, 2007). Organizado em conjunto com Claudia Lago, a coletânea orienta pesquisadores, da graduação à pós-graduação, sobre como qualificar suas pesquisas no campo jornalístico a partir de métodos multidisciplinares e de exemplos de casos aplicados.

Cremilda Medina é a estudiosa do campo referenciada pela maior variabilidade de produções. O que pode ser compreendido por ser uma autora que atravessa cinco décadas com frutífera contribuição ao campo desde a sua dissertação, intitulada Estrutura da mensagem jornalística, defendida na década de 1970, em que investigou a notícia nos contextos urbano e industrial, sendo a primeira pesquisa realizada pelo Programa de Pós- 


\section{REVISTA PAUTA GERAL}

\section{ESTUDOS EM JORNALISMO}

10.5212/RevistaPautaGeral.v.6.i2.00013

Graduação em Ciências da Comunicação (PPGCOM) da USP, marcando seu pioneirismo nos estudos sobre jornalismo. A trajetória da autora se entremeou ainda nos estudos sobre o diálogo possível, o modo do jornalista constituir sua função mediadora e de articulação das forças simbólicas, até a defesa de recursos de afeto e de complexidade ao profissional da informação da atualidade.

\section{Considerações finais}

Parece incipiente e redutor o lugar que as teorias brasileiras do jornalismo estão resguardando às mulheres no campo científico, pesquisadoras que com afinco contribuíram para o enriquecimento das práticas de uma profissão fundamental para a compreensão da contemporaneidade. O apagamento do trabalho acadêmico e do esforço intelectual que elas realizaram por meio de suas pesquisas apenas reforça a manutenção das estruturas opressivas hoje postas que impedem, por exemplo, as mulheres trabalhadoras de ascenderem profissionalmente, fragilizando seus trabalhos, suas vidas e suas reflexões acadêmicas.

As discussões aqui tecidas reivindicam a quebra das assimetrias, a diminuição das desigualdades tendo em vista a presença expressiva das mulheres no mundo do trabalho do jornalismo e no mundo da pesquisa acadêmica. E para que essas desconstruções estruturais aconteçam é necessário apontar lugares em que a transformação possa se dar. Afinal, como ressalta hooks,

Ao falhar na criação de um movimento educacional de massa para ensinar a todo mundo sobre feminismo, permitimos que a mídia de massa patriarcal permanecesse como o principal local em que as pessoas aprendem sobre feminismo, e a maioria do que aprendem é negativa (...). Se não trabalharmos para criar um movimento de massa que oferece educação feminista para todo mundo, homens e mulheres, teoria e prática feminista serão sempre enfraquecidas pela informação negativa produzida na maioria das mídias convencionais (HOOKS, 2019, p. 47-48).

Considerando que as universidades trazem em seus valores fundacionais a transformação da realidade, atentar para a paridade entre os gêneros na constituição dos referenciais bibliográficos e na composição do corpo docente, por exemplo, são atitudes sensíveis às mudanças e socialmente exemplares.

Se as mulheres matriarcas de nossos estudos foram apequenadas de nossa memória e do registro do conhecimento, tal estudo provocativo faz pensar: o que poderemos estar a fazer com intelectuais negras e negros, ou com pesquisadoras e 


\section{REVISTA PAUTA GERAL}

\section{ESTUDOS EM JORNALISMO}

10.5212/RevistaPautaGeral.v.6.i2.00013

pesquisadores vinculados a programas de pós-graduação e universidades situados em regiões desprivilegiadas economicamente?

Ao refletir sobre as várias formas nas quais e pelas quais o racismo é normalizado cotidianamente, Kilomba (2019) chama a atenção para a necessidade de um percurso de consciencialização coletiva que, pautado não na moral, mas em responsabilização, possa criar novas configurações de poder e conhecimento: "só quando se reconfiguram as estruturas de poder é que muitas identidades marginalizadas podem também, finalmente, reconfigurar a noção de conhecimento: Quem sabe? Quem pode saber? Saber o quê? E o saber de quem?" (KILOMBA, 2019, p.12-13; grifo da autora).

Em semelhante sentido, podemos dizer que a centralização dos referenciais teóricos em homens brancos, localizados em regiões privilegiadas do País, mina a possibilidade de construção de um panorama plural no futuro, com o desenvolvimento crítico das jornalistas e dos jornalistas e com a potência de um pensamento constitutivamente diverso sobre as experiências jornalísticas em território brasileiro.

\section{Referências}

ALMEIDA, Gabriela Cavalcanti Carneiro de. A mulher na pesquisa em jornalismo - teses e dissertações defendidas em Programas de Pós-Graduação em Jornalismo e Comunicação do Brasil (1972-2015). Dissertação (Mestrado em Jornalismo - Área de Concentração: Processos Jornalísticos), Universidade Estadual de Ponta Grossa, 2018.

BRASIL. MINISTÉRIO DA EDUCAÇÃO. Resolução CNE/CES 1/2013. Institui as Diretrizes Curriculares Nacionais para o curso de graduação em Jornalismo, bacharelado, e dá outras providências. Diário Oficial da União, Brasília, $1^{\circ}$ de outubro de 2013, Seção 1, p. 26.

BRASIL. MINISTÉRIO DA EDUCAÇÃO. Resolução CNE/CP 1/2012. Estabelece Diretrizes Nacionais para a Educação em Direitos Humanos. Diário Oficial da União, Brasília, 31 de maio de 2012, Seção 1, p. 48.

BRASIL. MINISTÉRIO DA EDUCAÇÃO. Resolução CNE/CP 1/2004. Institui Diretrizes Curriculares Nacionais para a Educação das Relações Étnico Raciais e para o Ensino de História e Cultura Afro-Brasileira e Africana. Diário Oficial da União, Brasília, 22 de junho de 2004, Seção 1, p. 11.

DESLAURIERS, Jean-Pierre; KÈRSITI, Michèle. O delineamento de pesquisa qualitativa. In POUPART, Jean et al. A pesquisa qualitativa: enfoques epistemológicos e metodológicos. Petrópolis: Vozes, 2008. 


\section{REVISTA PAUTA GERAL}

\section{ESTUDOS EM JORNALISMO}

10.5212/RevistaPautaGeral.v.6.i2.00013

FIGARO, Roseli. O mundo do trabalho das jornalistas: feminismo e discriminação profissional. Brazilian Journalism Research (BJR), v. 14. $\mathrm{n} \cong 2$ 2, 2018. Disponível em: https://bjr.sbpjor.org.br/bjr/article/viewFile/1052/pdf_1. Acesso em: 10 out. 2019.

FIGARO, Roseli; NONATO, Claudia; GROHMANN, Rafael (Orgs.). As mudanças no mundo do trabalho do jornalista. São Paulo: Atlas, 2013.

HOOKS, bell. Ensinando a transgredir: a educação como prática da liberdade. Tradução: Marcelo Brandão Cipolla - São Paulo: Editora WMF Martins Fontes, 2013.

O feminismo é para todo mundo: políticas arrebatadoras. $5^{\underline{a}}$ ed. Rio de Janeiro: Rosa dos Ventos, 2019.

HARAWAY, Donna. Saberes localizados: a questão da ciência para o feminismo e o privilégio da perspectiva parcial. Cadernos Pagu, n. 5, 1995, p. 07-41. Disponível em: https://periodicos.sbu.unicamp.br/ojs/index.php/cadpagu/article/view/1773/1828. Acesso em: 10 jul. 2019.

KILOMBA, Grada. Memórias da plantação - Episódios de racismo cotidiano. Rio de Janeiro: Cobogó, 2019

LELO, Thales Vilela. Reestruturações produtivas no mundo do trabalho dos jornalistas: precariedade, tecnologia e manifestações da identidade profissional. 2019. Tese (Doutorado em Ciências Sociais), Instituto de Filosofia e Ciências Humanas, Universidade Estadual de Campinas, São Paulo.

MEDINA, Cremilda (org.). Ciência e sociedade: mediações jornalísticas. Série Novo Pacto da Ciência 8. São Paulo: CCS/USP, 2005.

MICK, Jacques., LIMA, Samuel. Perfil do jornalista brasileiro: características demográficas, políticas e do trabalho jornalístico em 2012. Florianópolis, Insular, 2012.

MORAES, Fabiana; VEIGA DA SILVA, Marcia. A objetividade jornalística tem raça e tem gênero: a subjetividade como estratégia descolonizadora. Anais do XXVIII Encontro Anual da Compós. Pontifícia Universidade Católica do Rio Grande do Sul, Porto Alegre, 2019.

PIRES, Álvaro. Amostragem e pesquisa qualitativa: ensaio teórico e metodológico. In: POUPART, Jean et al. A pesquisa qualitativa: enfoques epistemológicos e metodológicos. Petrópolis: Vozes, 2008.

RAGO, Margareth. Epistemologia feminista, gênero e história. In: PEDRO, Joana; GROSSI, Miriam (orgs.). Masculino, feminino, plural. Florianópolis: Ed. Mulheres, 1998. 